\title{
Brain damage in fatal non-missile head injury without high intracranial pressure
}

\author{
D I GRAHAM, AUDREY E LAWRENCE, J HUME ADAMS, D DOYLE, \\ D R MCLELLAN
}

From the Department of Neuropathology, University of Glasgow, Scotland

SUMMARY As part of a comprehensive study of brain damage in 635 fatal non-missile head injuries, the type and prevalence of brain damage occurring in the absence of high intracranial pressure were analysed. Of 71 such cases, 53 sustained their injury as a result of a road traffic accident; only 25 experienced a lucid interval. Thirty eight had a fractured skull, a mean total contusion index of 12.9 and diffuse axonal injury in 29: severe to moderate ischaemic damage was present in the cerebral cortex in 25 , brain swelling in 13 , and acute bacterial meningitis in nine. The prevalence and range of brain damage that may occur in the absence of high intracranial pressure are important to forensic pathologists in the medicolegal interpretation of cases of fatal head injury.

When a pathologist is about to perform necropsy on a patient who has died as a result of a head injury, there is a tendency to assume that gross structural damage will be obvious, and that a high intracranial pressure has been a major contributing factor to death. Indeed, intracranial haematoma often succeeds a head injury, particularly if the patient has a fracture of the skull.' In our experience, however, fatal non-missile head injury in the absence of high intracranial pressure is quite common. The brain damage in such cases is often not easy to identify, and the following analysis of our experience may help pathologists who find no evidence of intracranial haemorrhage or high intracranial pressure in a fatal head injury.

\section{Material and methods}

Between 1968 and 1982 full necropsies were performed on 635 patients with non-missile head injuries who had been managed by the department of neurosurgery at this institute. There were 497 males and 138 females, aged 9 weeks to 89 years (median 36 years); the duration of survival ranged from one hour to fourteen years and three months (median two to three days). The brains and spinal cords were fixed in $10 \%$ formol saline for at least three weeks before dissection. The cerebral hemispheres were cut in a standard fashion ${ }^{2}$ in the coronal plane, the cerebellum at right angles to the folia, and the brain stem horizontally. Comprehensive

Accepted for publication 14 July 1987 histological studies, including the examination of large celloidin sections of the brain, were carried out on 434 of the 635 cases. Macroscopic and histological abnormalities were recorded on a series of line diagrams of the cerebral hemispheres, the cerebellum, and the brain stem. All abnormalities were then transferred to a proforma and the data stored and analysed on the University of Glasgow's mainframe computer. The clinical records of patients were assessed for evidence of a lucid interval before deterioration in the conscious level. ${ }^{3}$

The present analysis is limited to the 434 cases in which comprehensive histological studies were undertaken. Using the criterion of pressure necrosis in one or both parahippocampal gyri as evidence of high intracranial pressure during life ${ }^{4}$ the cases were divided into two groups: those in which there was pressure necrosis in one or both parahippocampal gyri $(n=324)$; and those in which there was no such pressure necrosis $(n=110)$. There are cases, however, when there was clinical (intracranial pressure monitoring) ${ }^{4}$ or radiological evidence (occlusion of basal cisterns on computed tomography scan) ${ }^{5}$ that intracranial pressure should have been high during life, yet pressure necrosis was not found in the parahippocampal gyrus after death. This is usually because survival was too short to permit structural changes in the parahippocampal gyrus, or because a haematoma was evacuated very soon after injury, or some other type of decompressive procedure was carried so that there was no time for structural changes to occur in the parahippocampal gyrus. ' There were 39 
such cases in our series and they were therefore also excluded from the present series.

The total contusion index ${ }^{6}$ takes into account the depth and extent of contusions in various parts of the brain: 0 means that there were no contusions, a contusion index in the 20's is indicative of moderately severe contusions, while one of more than 37 is indicative of severe contusions.

\section{Results}

In 71 of the 434 cases there was no evidence (clinical, radiological, or pathological) that the intracranial pressure had been high during life. This group comprised 54 males and 17 females with an age range between 3 months to 83 years (mean 37, SD 24.6) (table 1) and a duration of survival between two hours and 14 years (median four to seven days) (table 2). Most injuries were sustained as a result of road traffic accidents $(n=53,75 \%)$ or falls $(n=9,13 \%)$, or from being crushed $(n=8,12 \%)$. Fewer patients $(n=25,35 \%)$ experienced a lucid interval than those in whom the intracranial pressure had been high. There was a fracture of the skull in only $38(54 \%)$ of the cases and diffuse axonal injury in $29(41 \%){ }^{7}$ There were no clinically intracranial haematomas. There were 15 cases $(21 \%)$ without contusions: the mean total contusion index in the remaining cases was 12.9. In most cases death was due to medical complications such as bronchopneumonia, pulmonary embolism, sepsis and renal failure.

Severe or moderately severe ischaemic damage was identified in 25 of the 71 cases (35\%). Of these 25 cases, there were nine with diffuse necrosis of neurons; nine in which the ischaemic damage was centred on the boundary zones between the major arterial territories, particularly between the anterior and middle cerebral arterial territories; two in which the ischaemic damage was centred on the middle or anterior cerebral arterial territories (in both of which the ischaemic damage was

Table 1 Distribution by age

\begin{tabular}{llllllllll}
\hline & \multicolumn{9}{c}{ Age in decades } \\
& $I$ & 2 & 3 & 4 & 5 & 6 & 7 & 8 & 9 \\
\hline No. of cases & 11 & 10 & 14 & 4 & 5 & 9 & 8 & 8 & 2 \\
\hline
\end{tabular}

also accentuated in the boundary zones); and five in which there was a combination of multiple sulcal infarcts and either infarction within the distribution of the superior cerebellar or the posterior inferior cerebellar arteries, or in the boundary zone between these two arterial territories. In addition to ischaemic lesions in the cerebral cortex, there were 23 cases in which there was ischaemic damage in the hippocampus or in the basal ganglia, or both. Of the remaining 46 cases, there were 25 in which the ischaemic damage was mild, leaving only 21 cases in which there was no ischaemic brain damage.

There was swelling of the brain in 13 cases. In 10 of these the swelling was bilateral and was attributable to ischaemic damage in two, to contusions, in three, and to a combination of ischaemic damage, and to contusions in five. In the remaining three cases the unilateral hemispheric swelling was attributed to contusions. In nine cases there was acute bacterial meningitis. Cerebral fat embolism was identified in two cases.

Cross tabulation between the two most commonly found neuropathological features in these casesnamely, severe to moderate ischaemic brain damage and diffuse axonal injury-is shown in table 3. There was no significant association between these features.

\section{Discussion}

A high intracranial pressure and internal herniation undoubtedly contribute to fatalities in cases of nonmissile head injury, but the prevalence of certain types of brain damage in the absence of a high intracranial pressure is of particular importance to forensic pathologists who may be confronted with a brain, which externally, may show little or no macroscopic abnormalities.

It has been shown previously that a good indicator of a high intracranial pressure due to a supratentorial space occupying mass is the presence of a wedge of pressure necrosis in one or both parahippocampal gyri that develops along the line of a tentorial hernia when the gyrus becomes impacted against the free edge of the tentorium cerebelli. ${ }^{4}$ That this is not apparent in all cases is probably due to the fact that during the period of spatial compensation some degree of shift and herniation of the brain can occur without the

Table 2 Distribution by survival

\begin{tabular}{|c|c|c|c|c|c|c|c|c|c|c|}
\hline & \multicolumn{10}{|c|}{ Duration of survival } \\
\hline & \multicolumn{4}{|c|}{ Days } & \multicolumn{2}{|c|}{ Weeks } & \multicolumn{4}{|c|}{ Months } \\
\hline & $<1$ & $1-2$ & $2-3$ & $3-7$ & $1-2$ & $2-4$ & $1-3$ & $3-6$ & $6-12$ & $>12$ \\
\hline No. of cases & 17 & 9 & 3 & 12 & 8 & 8 & 10 & 1 & 1 & 2 \\
\hline
\end{tabular}


Table 3 Association between severe/moderate ischaemic damage and diffuse axonal injury

\begin{tabular}{llll}
\hline & \multicolumn{3}{l}{ Diffuse axonal injury } \\
\cline { 2 - 4 } $\begin{array}{l}\text { Severe/moderate ischaemic } \\
\text { damage }\end{array}$ & Absent & Present & Total \\
\hline Absent & 26 & 20 & 46 \\
Present & 16 & 9 & 25 \\
Total No & 42 & 29 & 71 \\
\hline
\end{tabular}

intracranial pressure becoming dangerously high. ${ }^{8}$ There are, however, cases in which types of brain damage conventionally associated with a high intracranial pressure are present in the absence of pressure necrosis in the parahippocampal gyri. The pathologist then has to accept that there are occasions when supratentorial intracranial pressure was high during life, but when the parahippocampal gyri are normal.'

In our study three quarters of the patients sustained their head injury as a result of a road traffic accident, and some two thirds did not have a lucid interval. There was a fracture of the skull in $54 \%$, which was considerably less than in patients in whom the intracranial pressure had been high during life.' Contusions and lacerations are the typical hallmarks of brain damage caused by head injury. In our cases the severity of contusions varied widely, ranging from the 15 cases $(21 \%)$ in which there were no contusions to those in which the contusions were severe: the median of the total contusion index, however, was only 6 , this contrasting with a contusion index of 17.5 in cases in which there was neuropathological evidence of the intracranial pressure having been high during life.' This indicates that in many cases the amount of contusional injury was only mild.

The commonest type of brain damage identified in this group of patients was diffuse axonal injury. This type of brain damage, first defined by Strich as diffuse degeneration of white matter, ${ }^{9}$ was present in $41 \%$ of the cases, and there is now good clinical and pathological evidence that patients with diffuse axonal injury form a distinct clinicopathological group in which immediate unconsciousness unaccompanied by an intracranial mass lesion is the rule. ${ }^{7}$ The next most commonly found structural change was ischaemic brain damage, which was either severe or moderate in 25 cases. From the pattern and distribution of the damage, especially in the cortex, the pathogenesis of the lesion could be strongly suspected. For example, in nine of the cases there was diffuse ischaemic damage of the type associated with cardiac arrest or epilepsy. All the remaining ischaemic lesions were focal, from which it may be concluded that the ischaemic damage was due to a critical reduction in regional cerebral blood flow. ${ }^{10}$ Additional contributing factors were a reduced oxygen content of the blood ${ }^{12}$ and angiographic evidence of arterial spasm..$^{13}$ There is therefore no doubt that an insufficient supply of oxygenated blood to the brain was common in this group of patients.

A problem facing pathologists is that the brain swells after death..$^{14}$ Nevertheless, brain swelling during life was thought to be present in 13 of the 71 cases without evidence of a high intracranial pressure. In 10 it was bilateral and in three unilateral, the swelling being attributable to contusions, ischaemic brain damage, or a combination of factors. In none of the cases, however, was there diffuse swelling of the entire brain of the type that occurs mainly in children and adolescents, ${ }^{1617}$ as indicated during life by the evidence of small symmetrical ventricles and occlusion of the basal cisterns on computed tomography scans. ${ }^{5}$ The apparent discrepancy between brain swelling and the failure to find neuropathological evidence of a high intracranial pressure must again be ascribed to the matters already discussed, either singly or in combination, although it is well known that brain swelling secondary to diffuse hypoxia is rarely sufficient to cause internal herniation. ${ }^{18}$

Another and unexpectedly high complication of the original head injury was acute bacterial meningitis in nine cases. In eight of the cases there was a fracture of the skull, and in seven the meningitis developed as a late complication of the head injury after discharge from the neurosurgical unit.

For pathologists performing necropsies in cases of fatal head injury in the absence of intracranial haemorrhage or evidence of a high intracranial pressure appropriate investigations to establish whether the patient has sustained diffuse axonal injury or ischaemic brain damage must be carried out: both of these may be difficult or even impossible to establish without appropriate histological studies. ${ }^{610}$

The study was supported by an MRC Project Grant G8007342. We thank Mr L Miller and his staff for technical assistance and Mrs J Rubython for typing the manuscript.

\section{References}

1 Graham DI, Lawrence AE, Adams JH, Doyle D, McLellan DR. Brain damage in non-missile head injury secondary to a high intracranial pressure. Neuropathol Appl Neurobiol 1987;13: 209-17.

2 Adams JH, Murray MF. Atlas of post-mortem techniques in neuropathology. Cambridge: Cambridge University Press, 1982.

3 Reilly PL, Graham DI, Adams JH, Jennett B. Patients with head injuries who talk and die. Lancet 1975 ;ii:375-7.

4 Adams JH, Graham DI. The relationship between ventricular fluid pressure and the neuropathology of raised intracranial pressure. Neuropathol Appl Neurobiol 1976;2:323-32.

5 Teasdale E, Cardosa E, Galbraith S, Teasdale G. A new CT scan appearance with raised intracranial pressure in severe diffuse 
head injury. J Neurol Neurosurg Psychiatr 1984;47:600-3.

6 Adams JH, Doyle D, Graham DI, et al. The contusion index: a reappraisal in human and experimental non-missile head injury. Neuropathol Appl Neurobiol 1985;11:299-308.

7 Adams JH, Graham DI, Murray LS, Scott E. Diffuse axonal injury due to non-missile head injury in humans: analysis of 45 cases. Ann Neurol 1982;12:557-63.

8 Galbraith S, Teasdale G. Predicting the need for operation in the patient with an occult traumatic intracranial hematoma. $J$ Neurosurg 1981;55:75-81.

9 Strich SJ. Diffuse degeneration of the cerebral white matter in severe dementia following head injury. J Neurol Neurosurg Psychiatr 1956;19:163-85.

10 Adams JH, Brierley JB, Connor RCR, Treip CS. The effects of systemic hypotension upon the human brain. Clinical and neuropathological observations in 11 cases. Brain 1966;89: 235-68.

11 Graham DI, Adams JH, Doyle D. Ischaemic brain damage in fatal non-missile head injuries. $J$ Neurol Sci 1978;39:213-34.

12 Jennett $\mathrm{S}$. Pulmonary function in the head injured patient. In: Fitch W, Barker J, eds. Head injury and the anaesthetist. Amsterdam: Elsevier BV (Biomedical Division), 1985:53-82.
13 Macpherson P, Graham DI. Correlation between angiographic findings and the ischaemia of head injury. $J$ Neurol Neurosurg Psychiatr 1978:41:122-7.

14 Adams JH. The "respirator brain". Arch Neurol 1976;33:589.

15 Sarwar M, McCormick WF. Decrease in ventricular and sulcal size after death. Radiology 1978;127:409-11.

16 Zimmerman RA, Larissa T, Bilaniuk LT, Gennarelli TA. Computed tomography of shearing injuries of the cerebral white matter. Radiology 1978;127:393-6.

17 Bruce DA, Alavi A, Bilaniuk L, Kolinskas C, Obrist W, Uzzell B. Diffuse cerebral swelling following head injuries in children: the syndrome of "malignant brain oedema". $J$ Neurosurg 1981:54:170-8.

18 Brierley JB, Graham DI. Hypoxia and vascular disorders of the central nervous system. In: Adams JH, Corsellis JAN, Duchen LW, eds. Greenfield's neuropathology. 4th ed. London: Edward Arnold, 1984:125-207.

Requests for reprints to: Professor D I Graham, Department of Neuropathology, Institute of Neurological Sciences, Southern General Hospital, Glasgow, G51 4TF, Scotland. 